\title{
INHIBITION OF RIBOSOMAL AND RNA POLYMERASE FUNCTIONS BY RUBRADIRIN AND ITS AGLYCONE
}

\author{
Fritz REUSSER
}

The Upjohn Company, Kalamazoo, MI 49001, U.S.A.

(Received for publication September 17, 1979)

The antibiotic rubradirin is structurally related to the ansamycin family of antibiotics. Most members of this group act as specific inhibitors of bacterial RNAP*. Rubradirin and its aglycone possess diverging modes of action. Rubradirin inhibits ribosomal functions related to the peptide chain initiation process. It does not inhibit RNAP. By contrast the aglycone of rubradirin retains moderate inhibitory activity towards ribosomal functions but acts essentially as an extremely potent inhibitor of RNAP.

The antibiotic rubradirin acts as a selective inhibitor of enzymatic peptide chain initiation ${ }^{1,2)}$. Non-enzymatic initiation effected in the presence of high $\mathrm{Mg}^{2+}$ concentrations is not inhibited by rubradirin.

It was observed that impure rubradirin preparations or old stock solutions of the antibiotic, in addition to the properties mentioned above, exerted strong inhibitory activity against bacterial RNAP. Recently the chemical structure of rubradirin was determined and key fragments of the antibiotic became available. This allowed us to study these phenomena (viz. impairment of ribosomal and RNAP functions) as discussed in this paper.

The proposed chemical structure for rubradirin is shown in Fig. $1^{3,4}$. The antibiotic consists of four distinct moieties, a quinone, dihydroxydipicolinic acid, a coumarin and a nitrosugar. The quinone chromophore (rubransarol) is related to the ansamycins. Fig. 1. The proposed structure for rubradirin.

This moiety is linked through an ester bond to dihydroxydipicolinic acid. The hydroxydipicolinic acid in turn is glycosylated by a nitropyranose named rubranitrose. The fourth moiety is a substituted amide of coumarin linked to the hydroxypicolinic acid moiety via its amide.

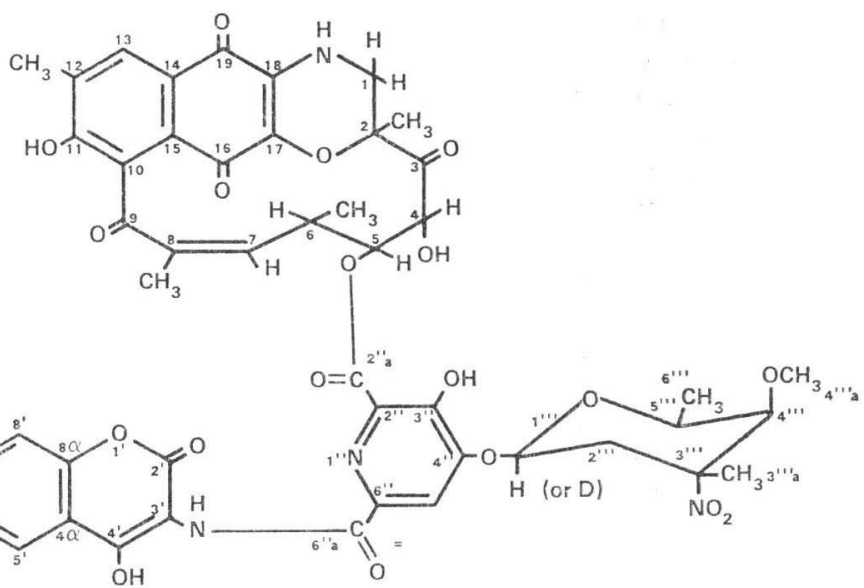

Rubradirin

* RNAP $=E$. coli RNA polymerase. 


\section{Methods}

Escherichia coli RNAP was isolated and assayed as described by CHAMBERLIN and BERG ${ }^{5)}$.

The Nirenberg type amino acid incorporation system was described previously ${ }^{11}$.

ATP-dependent DNA replication in toluenized E. coli $\mathrm{H} 560$ cells (poly $\mathrm{A}^{-}$) was assessed by the method of MOSES and RICHARDSON ${ }^{6)}$ and MOSES ${ }^{7}$.

Salt-washed $70 \mathrm{~S}$ ribosomes were prepared as described $^{22}$. E. coli tRNA ${ }_{\mathrm{F}}^{\mathrm{m}+1}$ was obtained from the Oak Ridge National Laboratories. Synthetase-transformylase enzyme required for the synthesis of fmet-tRNA $\mathrm{F}_{\mathrm{F}}$ was isolated by the procedure of DUBNofF and MaItra ${ }^{8)}$. [ $\left.{ }^{3}\right]$ fmet-tRNA $A_{F}$ was prepared as described by CASKEY et al. ${ }^{97}$ and had a specific activity of approximately $900 \mathrm{cpm} /$ pmole. Initiation factors were isolated from the first ribosomal salt wash fluid $^{8}$. $\quad \mathbf{R}_{17}$ phage RNA was purchased from Boehringer Mannheim.

Fig. 2. Definition of rubradirin fragments tested.

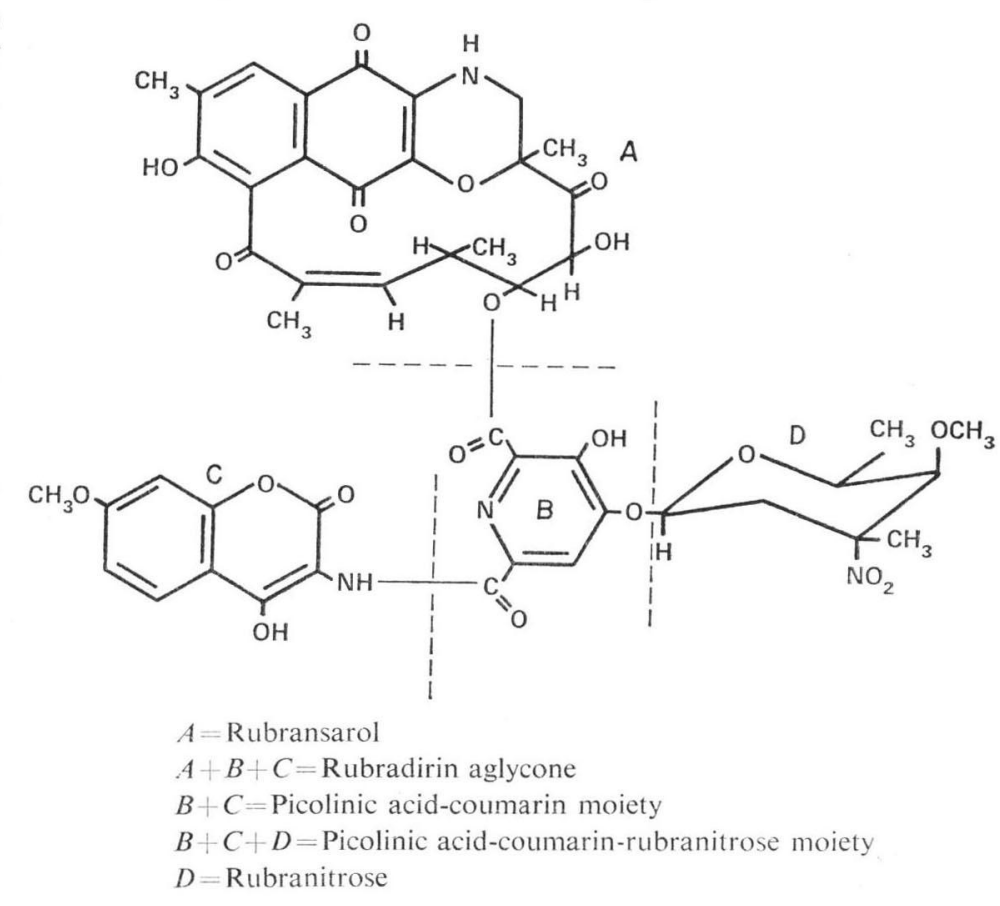

The binding of E. coli RNAP to template DNA was assessed by the Millipore membrane filtration technique described by JONES and BERG $^{10)}$.

The specific compositions of all the reaction mixtures and incubation conditions are given in the legends of the tables.

The rubradirin fragments tested are defined in Fig. 2.

\section{Results}

Stability of Rubradirin in Aqueous Solution

Rubradirin solutions of various ages showed one or the other of the following properties in terms of their mode of action: Fresh solutions would specifically inhibit protein synthesis only in cell-free test systems, older ones also inhibited RNAP functions.

The stability of rubradirin was thus inves-
Fig. 3. Effect of storage time on rubradirin solution as reffected by its inhibitory activity vs. peptide and RNA synthesis. The solution contained 0.13 $\mathrm{mm}$ rubradirin in $0.01 \mathrm{M} \mathrm{K}-\mathrm{PO}_{4}$ buffer, $\mathrm{pH} 7.8$. The cell-free poly(U)-directed phenylalanine incorporation system is defined in Table 1 and the RNA synthesis system in Table 2 .

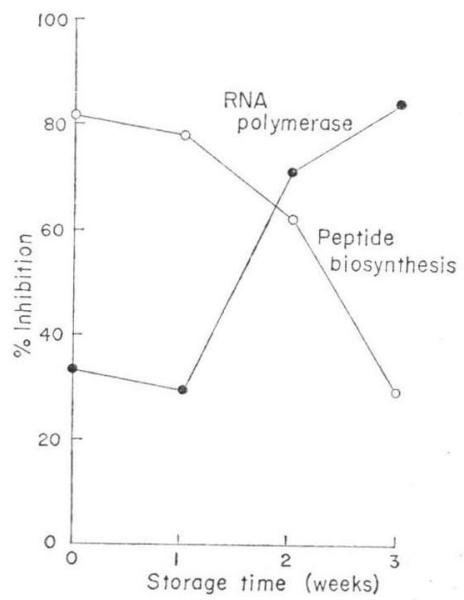


tigated upon extended storage in aqueous solution. Specifically a stock solution was prepared by dissolving approximately $1 \mathrm{mg}$ of pure rubradirin in $0.1 \mathrm{ml}$ dimethylformamide followed by sufficient $0.01 \mathrm{M} \mathrm{Na}-\mathrm{PO}_{4}$ buffer, $\mathrm{pH} 7.85$, to yield a final concentration of $0.13 \mathrm{~mm}$.

Following initial assay in specific cell-free test systems for protein and RNA synthesis the stock solution was stored at $4^{\circ} \mathrm{C}$ in the dark and reassayed at weekly intervals.

It was found that rubradirin is quite stable for a week under these conditions (Fig. 3). Thereafter the inhibitory potency against peptide synthesis decreased significantly while the inhibitory potency for RNAP increased accordingly. Hence it was apparent that an unknown reaction caused the slow, gradual conversion from one compound into another.

The eventual determination of the chemical structure of rubradirin and the availability of key rubradirin fragments allowed us to rationalize these stability phenomena.

Effect of Rubradirin Fragments on Cell-free Macromolecular Biosynthetic Systems

Peptide synthesis was carried out in a NIRENBERG type system measuring poly(U)-directed incorporation of $\left[{ }^{14} \mathrm{C}\right]$-phenylalanine. Intact rubradirin strongly inhibited this system as expected (Table 1). On the other hand rubransarol $\mathrm{A}$, the picolinic acid-coumarin and the picolinic acid-coumarinrubranitrose moieties showed only moderate inhibition of the reaction. This might be due to the pres-

Table 1. Effect of rubradirin fragments on poly (U)-directed phenylalanine incorporation system.

\begin{tabular}{|c|c|c|c|}
\hline \multicolumn{2}{|c|}{ Sample } & $\begin{array}{l}{\left[{ }^{14} \mathrm{C}\right] \text { Phenyl- }} \\
\text { alanine } \\
\text { incorporated } \\
\mathrm{cpm} / \text { sample }\end{array}$ & Inhibition \\
\hline \multicolumn{2}{|l|}{ Control, $15 \mathrm{~min}$} & 5,000 & 0 \\
\hline \multirow[t]{2}{*}{ Rubradirin } & $0.05 \mathrm{~mm}$ & 1,760 & 65 \\
\hline & $0.01 \mathrm{~mm}$ & 2,310 & 54 \\
\hline \multirow[t]{2}{*}{ Rubransarol A } & $0.05 \mathrm{~mm}$ & 3,440 & 32 \\
\hline & $0.01 \mathrm{~mm}$ & 4,890 & 3 \\
\hline \multicolumn{2}{|c|}{$\begin{array}{l}\text { Rubradirin-aglycon } \\
\qquad 0.05 \mathrm{~mm}\end{array}$} & 2,520 & 50 \\
\hline & $0.01 \mathrm{~mm}$ & 3,230 & 36 \\
\hline \multicolumn{2}{|c|}{$\begin{array}{cc}\text { Picolinic acid-coumarin } \\
\text { moiety } & 0.05 \mathrm{~mm}\end{array}$} & 4,260 & 15 \\
\hline & $0.01 \mathrm{~mm}$ & 5,920 & 0 \\
\hline \multicolumn{2}{|c|}{$\begin{array}{c}\text { Picolinic acid-coumarin- } \\
\text { rubranitrose moiety } \\
0.05 \mathrm{~mm}\end{array}$} & 3,560 & 29 \\
\hline & $0.01 \mathrm{~mm}$ & 4,400 & 13 \\
\hline
\end{tabular}

Reaction mixtures contained in a total volume of $0.25 \mathrm{ml}$ : Tris $\cdot \mathrm{HCl}$ buffer, $\mathrm{pH}$ 7.8, $100 \mathrm{~mm}$; magnesium acetate, $14 \mathrm{~mm}$; $\mathrm{KCl}, 60 \mathrm{~mm}$; ATP, $1 \mathrm{~mm}$; GPT, $0.03 \mathrm{~mm}$; mercaptoethanol, $6 \mathrm{~mm}$; phosphoenolpyruvate, K-salt, $75 \mathrm{~mm}$; pyruvate kinase (Calbiochem), $10 \mu \mathrm{g} ; \quad\left[{ }^{12} \mathrm{C}\right] \cdot$ amino acid mixture of 19 amino acids, $0.2 \mathrm{~mm}$ each; $\left[{ }^{14} \mathrm{C}\right]$. phenylalanine, $0.1 \mathrm{~mm}$ containing $1.75 \mu \mathrm{Ci}$ per sample; polyuridylate, $15 \mu \mathrm{g}$; S-30 enzyme, $430 \mu \mathrm{g}$ of protein. The samples were incubated at $37^{\circ} \mathrm{C}$ for 15 minutes.
Table 2. Effect of rubradirin fragments on RNA synthesis.

\begin{tabular}{|c|c|c|c|}
\hline \multicolumn{2}{|c|}{ Sample } & $\begin{array}{l}{\left[{ }^{14} \mathrm{C}\right] \cdot \mathrm{AMP}} \\
\text { incorporated } \\
\text { cpm/sample }\end{array}$ & Inhibition \\
\hline \multicolumn{2}{|l|}{ Control } & 5,020 & 0 \\
\hline \multirow[t]{2}{*}{ Rubradirin } & $0.05 \mathrm{~mm}$ & 4,440 & 12 \\
\hline & $0.01 \mathrm{~mm}$ & 5,060 & 0 \\
\hline \multirow[t]{2}{*}{ Rubransarol A } & $0.05 \mathrm{~mm}$ & 4,260 & 15 \\
\hline & $0.01 \mathrm{~mm}$ & 4,260 & 15 \\
\hline \multicolumn{2}{|c|}{$\begin{array}{l}\text { Rubradirin-aglycone } \\
\qquad 0.05 \mathrm{~mm}\end{array}$} & 220 & 96 \\
\hline & $0.01 \mathrm{~mm}$ & 135 & 98 \\
\hline \multicolumn{2}{|c|}{ Picolinic acid-coumarin } & & \\
\hline morety & $0.01 \mathrm{~mm}$ & 3,750 & $\begin{array}{l}01 \\
25\end{array}$ \\
\hline \multicolumn{2}{|c|}{$\begin{array}{l}\text { Picolinic acid-coumarin- } \\
\text { rubranitrose moiety } \\
0.05 \mathrm{~mm}\end{array}$} & 4,190 & 17 \\
\hline Congo red & $0.01 \mathrm{~mm}$ & 180 & 97 \\
\hline
\end{tabular}

The assay mixtures contained in a total volume of $0.25 \mathrm{ml}$ : tris (hydroxymethyl)aminomethane hydrochloride buffer ( $\mathrm{pH} 7.9$ ), $5 \mu \mathrm{mol} ; \mathrm{MgCl}_{2}$, $1 \mu \mathrm{mol}$; mercaptoethanol, $3 \mu \mathrm{mol} ; \mathrm{MnCl}_{2}, 0.25$ $\mu \mathrm{mol}$; GTP, UTP, and CTP, $0.1 \mu \mathrm{mol}$ each; $\left[8-{ }^{14} \mathrm{C}\right]$ ATP, $0.1 \mu \mathrm{mol}, 0.05 \mu \mathrm{Ci}$; poly[d(A-T)], $0.04 \mathrm{OD}_{260}$ units $/ \mathrm{ml}$; and polymerase, $0.5 \mathrm{U}$. Reactions were run at $37^{\circ} \mathrm{C}$ for 15 minutes and terminated by the addition of $3 \mathrm{ml}$ of cold $3.5 \%$ perchloric acid per tube. The acid-insoluble product was collected on Millipore filters, washed, and assayed for radioactivity. 
ence of small traces of contaminant intact rubradirin in these preparations. The aglycone of rubradirin caused significant inhibition of the test system although the extent of inhibition was clearly inferior to that of rubradirin itself.

Intact rubradirin did not impair RNA synthesis effected by E. coli RNAP (Table 2). The aglycone of rubradirin on the other hand caused complete cessation of RNA synthesis. The remaining fragments showed marginal inhibition which might be attributable to trace impurities present in these preparations as reasoned above. The only exception is the picolinic acid-coumarin moiety which did inhibit the reaction to the extent of $61 \%$ at $0.05 \mathrm{~mm}$.

Lastly, we investigated the effect of the compounds under study on replicative DNA synthesis in toluenized E. coli cells. None of the fragments inhibited this system to a significant extent (Table 3). Novobiocin is a specific inhibitor of this system ${ }^{11,12)}$. In this context it is of interest to note that novobiocin contains a coumarin moiety as does rubradirin. This structure is essential in novobiocin for the exertion of inhibitory activity on DNA replication (REUSSER, unpublished results).

These experiments confirmed our earlier findings that intact rubradirin acts as a specific inhibitor of protein synthesis. In addition the results show that the aglycone of rubradirin is less active in inhibiting protein synthesis but strongly inhibits the function of the enzyme RNAP. We also established earlier that rubradirin specifically inhibits the formation of enzymatic peptide chain initiation complexes meaning that it prevents the formation of or dissociates preformed fmet-tRNA $\mathrm{F}_{\mathrm{F}}-\mathrm{mRNA}$-ribosome complexes.

Rubradirin aglycone on the other hand inhibits non-enzymatic peptide chain initiation as well although only to a moderate extent (results not shown).

Table 3. Effect of rubradirin fragments on replicative DNA synthesis.

\begin{tabular}{|c|c|c|c|}
\hline \multicolumn{2}{|l|}{ Sample } & $\begin{array}{l}{\left[{ }^{3} \mathrm{H}\right] \cdot \text { TMP }} \\
\text { incorporated } \\
\text { cpm/sample }\end{array}$ & Inhibition \\
\hline \multicolumn{2}{|l|}{ Control } & 7,890 & 0 \\
\hline \multirow[t]{2}{*}{ Rubradirin } & $0.05 \mathrm{~mm}$ & 7,480 & 5 \\
\hline & $0.01 \mathrm{~mm}$ & 7,630 & 4 \\
\hline \multirow[t]{2}{*}{ Rubransarol A } & $0.05 \mathrm{~mm}$ & 7,150 & 10 \\
\hline & $0.01 \mathrm{~mm}$ & 7,160 & 10 \\
\hline \multicolumn{2}{|c|}{$\begin{array}{l}\text { Rubradirin aglycone } \\
0.05 \mathrm{~mm}\end{array}$} & 7,280 & 0 \\
\hline & $0.01 \mathrm{~mm}$ & 7,150 & 10 \\
\hline \multicolumn{2}{|c|}{ Picolinic acid-coumarin } & 9,630 & 8 \\
\hline & $0.01 \mathrm{~mm}$ & 7,080 & 10 \\
\hline \multicolumn{2}{|c|}{$\begin{array}{l}\text { Picolinic acid-coumarin- } \\
\text { rubranitrose moiety } \\
0.05 \mathrm{mM}\end{array}$} & 6,270 & 21 \\
\hline & $0.01 \mathrm{~mm}$ & 5,980 & 24 \\
\hline
\end{tabular}

Reaction mixtures contained in a total volume of $0.3 \mathrm{ml}$ : Tris $\cdot \mathrm{HCl}$ buffer, $\mathrm{pH} 8.0,50 \mathrm{~mm} ; \mathrm{KCl}$, $0.1 \mathrm{M}$; $\mathrm{Mg} \cdot$ acetate, $10 \mathrm{~mm}$; ATP, $2 \mathrm{~mm}$; dCTP, dGTP, dATP, $0.5 \mathrm{~mm}$ each; $\left[{ }^{3} \mathrm{H}\right] \cdot$ TTP, $0.02 \mathrm{~mm}$ containing $2.5 \mu \mathrm{C} /$ sample and approximately $2 \times$ $10^{9} \mathrm{E}$. coli cells/sample. Incubation of the reaction mixtures was for 30 minutes at $37^{\circ} \mathrm{C}$.
The results obtained indicate that the aglycone of rubradirin must possess a high affinity for RNAP. It was thus of interest to test the

Table 4. Effect of rubradirin and its aglycone on the formation of template DNA-RNA polymerase complexes

\begin{tabular}{|c|c|c|c|}
\hline \multicolumn{2}{|c|}{ Sample } & $\begin{array}{c}{\left[{ }^{14} \mathrm{C}\right] \cdot E \text {. coli }} \\
\text { DNA retained } \\
\text { cpm/sample }\end{array}$ & Inhibition \\
\hline \multicolumn{2}{|l|}{ Control } & 6,910 & 0 \\
\hline \multirow[t]{2}{*}{ Rubradirin } & $0.05 \mathrm{~mm}$ & 6,685 & 4 \\
\hline & $0.01 \mathrm{~mm}$ & 6,720 & 3 \\
\hline \multicolumn{2}{|c|}{$\begin{array}{l}\text { Rubradirin aglycone } \\
0.05 \mathrm{mM}\end{array}$} & 950 & 87 \\
\hline & $0.01 \mathrm{~mm}$ & 1,950 & 72 \\
\hline Congo red & $0.01 \mathrm{~mm}$ & 940 & 87 \\
\hline
\end{tabular}

Reaction mixtures contained in a total volume of $0.25 \mathrm{ml}$ : Tris(hydroxymethyl)aminomethane-hydrochloride, $\mathrm{pH} 7.9,0.04 \mathrm{M} ; \mathrm{MgCl}_{2}, 0.01 \mathrm{M}$; ethylenediaminetetraacetic acid, $0.1 \mathrm{~mm}$; dithiothreitol, $0.1 \mathrm{~mm}$; $\mathrm{KCl}, 0.15 \mathrm{~mm}$; RNA polymerase, $0.4 \mathrm{U}$; E. coli $\left[{ }^{14} \mathrm{C}\right] \cdot$ labeled DNA, $0.1 \mu \mathrm{g}$ containing approximately $8,000 \mathrm{cpm}$. The reaction was initiated by the addition of RNA polymerase last. The samples were incubated for 5 minutes at $37^{\circ} \mathrm{C}$. 
Table 5. Effect of rubradirin and its aglycone on the stability of DNA-RNAP complexes.

\begin{tabular}{|c|c|c|c|}
\hline \multicolumn{2}{|c|}{ Sample } & $\begin{array}{c}{\left[{ }^{\left[{ }^{14} \mathrm{C}\right]} \cdot \text { E. coli }\right.} \\
\text { DNA retained } \\
\text { cpm/sample }\end{array}$ & Inhibition \\
\hline \multicolumn{2}{|l|}{ Control } & 6,290 & 0 \\
\hline \multirow[t]{2}{*}{ Rubradirin } & $0.05 \mathrm{~mm}$ & 6,470 & 0 \\
\hline & $0.01 \mathrm{~mm}$ & 6,320 & 0 \\
\hline \multicolumn{2}{|c|}{$\begin{array}{c}\text { Rubradirin aglycone } \\
0.05 \mathrm{~mm}\end{array}$} & 1,030 & 84 \\
\hline & $0.01 \mathrm{~mm}$ & 3,200 & 50 \\
\hline Congo red & $0.01 \mathrm{~mm}$ & 870 & 87 \\
\hline
\end{tabular}

Reaction mixtures were as described in the legend to Table 6 . The DNA-RNAP complex was preformed by incubating the sample for 5 minutes at $37^{\circ} \mathrm{C}$; antibiotics were then added, and incubation was continued for an additional 5 minutes.

effects of rubradirin aglycone on the formation or stability of template DNA-RNAP complexes. Rubradirin itself did not impair the formation of this complex (Table 4). In contrast its aglycone strongly inhibited this reaction as did congo red.

If the DNA-RNAP complexes were preformed and then exposed to the same inhibitors, rubradirin again did not impair the stability of the complex; congo red caused complete dissociation of the complex (Table 5). Rubradirin aglycone dislodged the polymerase from its DNA template although the extents of inhibition were somewhat lower when compared to the corresponding data obtained for complex formation. This suggests that rubradirin aglycone is somewhat more effective in preventing the formation of DNA-RNAP complexes than in inducing their dissociation.

Rubradirin acts as a strong inhibitor of enzymatic peptide chain initiation and thus prevents the formation of ternary fmet-tRNA $\mathrm{F}_{\mathrm{F}}-\mathrm{mRNA}$-ribosome complexes. The rubradirin fragments on hand were also tested in such an initiation system. Rubradirin strongly inhibited this reaction as expected (Table 6). The aglycone of rubradirin acted also as a strong inhibitor of the reaction. All the other fragments as well as congo red did not affect initiation to any drastic extent thus corroborating the results obtained in the NirenBerg system (Table 1).

\section{Discussion}

The antibiotic rubradirin contains an ansamycin-like moiety and is in this respect related to a family of antibiotics known as the ansamycins. Most members of this group (rifamycins, streptovaricins, tolypomycins) act as very potent inhibitors of bacterial RNAP ${ }^{13}$. Intact rubradirin, however, does not impair the function of RNAP but instead inhibits bacterial protein synthesis.

By contrast, the aglycone of rubradirin retains some inhibitory activity toward protein synthesis

Effect of rubradirin fragments on enzym-

\begin{tabular}{|c|c|c|c|}
\hline \multicolumn{2}{|c|}{ Sample } & $\begin{array}{c}{\left[{ }^{3} \mathrm{H}\right] \cdot \mathrm{fmet}_{-}} \\
\text {tRNA } \\
\text { bound, } \\
\text { cpm/sample }\end{array}$ & $\begin{array}{c}\% \\
\text { Inhibition }\end{array}$ \\
\hline \multicolumn{2}{|l|}{ Control } & 1,920 & 0 \\
\hline \multirow{2}{*}{ Rubradirin } & $0.05 \mathrm{~mm}$ & 520 & 73 \\
\hline & $0.01 \mathrm{~mm}$ & 560 & 71 \\
\hline \multicolumn{2}{|c|}{ Control } & 1,650 & 0 \\
\hline \multicolumn{2}{|c|}{ Rubransarol A $0.05 \mathrm{~mm}$} & 1,390 & 17 \\
\hline & $0.01 \mathrm{~mm}$ & 1,920 & 0 \\
\hline \multicolumn{4}{|c|}{ Rubradirin-aglycone } \\
\hline & $0.01 \mathrm{~mm}$ & 450 & 73 \\
\hline \multicolumn{4}{|c|}{ Picolinic acid-coumarin } \\
\hline & $0.01 \mathrm{~mm}$ & 1,360 & 18 \\
\hline \multicolumn{4}{|c|}{$\begin{array}{l}\text { Picolinic acid-coumarin- } \\
\text { rubranitrose moiety }\end{array}$} \\
\hline & $0.01 \mathrm{~mm}$ & 1,460 & 12 \\
\hline Congo red & $0.01 \mathrm{~mm}$ & 1,350 & 19 \\
\hline
\end{tabular}

The reaction mixtures contained in a total volume of $0.15 \mathrm{ml} ; 50 \mathrm{~mm}$ Tris. $\mathrm{HCl}, \mathrm{pH} 7.8 ; 100 \mathrm{~mm}$ 2 mM GTP; 0.5 OD units of $\mathrm{R}_{12}$ phage $\mathrm{RNA}$ $4.5 \mathrm{OD}_{260}$ units of $70 \mathrm{~S}$ ribosomes; $0.11 \mathrm{OD}_{260}$ were incubated at $37^{\circ} \mathrm{C}$ for 15 minutes. Further processing of the samples was as described (REUsSER, 1973b). 
but proves to be an extremely potent inhibitor of the enzyme RNAP. The specific mode of action of rubradirin aglycone on RNAP differs significantly from the one exerted by streptolydigin or rifamycins. These latter agents cause cessation of initiation or de novo RNA synthesis but do not prevent the binding of the polymerase to its initiation site on the DNA template ${ }^{14,15)}$. On the other hand rubradirin aglycone as well as congo red prevent the attachment of RNAP to its promoter sites on the DNA template and dissociate preformed DNA-RNAP complexes.

The specific action of rubradirin aglycone on RNAP is thus more related to the one exerted by congo red and not to the ansamycins.

The highly methylated nitro-sugar present in rubradirin must play a pivotal role in the ability of rubradirin and its aglycone to either affect protein or RNA synthesis: In the glycosylated form the antibiotic inhibits protein synthesis only, as an aglycone it primarily inhibits RNA synthesis and inhibits protein synthesis to a lesser extent.

Rubradirin $\mathrm{B}$ was also isolated from rubradirin fermentations in small quantities ${ }^{16}$. It lacks the hydroxyl group at position 4 of the dipicolinic acid which is glycosylated in rubradirin. Consequently it lacks rubranitrose. In addition, rubradirin B differs slightly from rubradirin itself in the stereochemistry at $\Delta^{7}$ of the ansachromophore which is trans in the case of rubradirin B (Fig. 1). Surprisingly rubradirin $\mathrm{B}$ does not impair the function of RNAP at all but exclusively affects ribosomal functions and that to a much lesser extent than rubradirin. This observation suggests that the non-glycosylated hydroxyl group as present in rubradirin aglycone is probably essential for interaction with RNAP. The significance of the minor stereochemical difference between rubradirin and rubradirin $\mathrm{B}$ within the ansamycin chromophore is more difficult to assess.

Rubradirin only prevents enzymatic peptide chain initiation and thereby affects the initiator site on the $30 \mathrm{~S}$ ribosomal subunit. In more general terms this region represents a nucleic acid binding site. The aglycone of rubradirin also impairs the ribosomal initiator site but shows less specificity toward this site as it inhibits enzymatic as well as non-enzymatic initiation. In addition rubradirin aglycone possesses a very strong affinity for RNAP and more specifically for the template nucleic acid binding site of this enzyme. This latter conclusion is supported by the fact that the aglycone prevents the attachment of RNAP to its template. Ribosomes and RNAP differ significantly from each other in terms of structure and function. However, the simplest interpretation of our results is that rubradirin aglycone interacts with the nucleic acid binding sites as present in RNAP and at the initiator tRNA binding site on the ribosome. Rubradirin on the other hand recognizes only the binding site as present on the initiating ribosome. This in turn suggests some common structural features for the respective nucleic acid binding pockets as present on either RNAP or the ribosome. It is also interesting to note that neither of the two inhibitors under discussion inhibits DNA replication as assessed in a toluenized E. coli system. This infers that the template binding site of the replicase differs from the ones present in RNAP or the ribosomal initiator tRNA site.

In terms of antibacterial activity against whole bacterial cells rubradirin is an extremely potent growth inhibitor. The drug, is therefore, capable to penetrate the bacterial cell envelope. The aglycone of rubradirin, although extremely potent in cell-free systems, shows modest growth inhibitory activity vs. whole cells. This latter compound is thus an inefficient penetrator of the cellular envelope.

\section{Acknowledgment}

The technical assistance of Mr. J. KAY is gratefully acknowledged. I also thank Dr. H. HoEkSEMA for supplying us with the rubradirin fragments studied.

\section{References}

1) Reusser, F.: Rubradirin, an inhibitor of ribosomal polypeptide biosynthesis. Biochemistry 12: 1136 1143,1973

2) Reusser, F.: Rubradirin, a selective inhibitor of initiation factor dependent peptide chain initiation. Biochemistry 12: 4524 4528, 1973

3) Hoeksema, H.; S. A. Mizsak, C. Chidester \& L. Baczynsky: The structure of rubradirin. Abstr. 18th 
Interscience Conference on Antimicrobial Agents and Chemotherapy $¥ 170,1978$

4) Hoeksema, H.; C. Lewis, S. A. Mizsak, J. A. Shiley, D. R. Wait, H. A. Whaley \& G. E. Zurenko: The isolation and characterization of rubradirin B. J. Antibiotics 31: 945 948, 1978

5) Chamberlin, M. \& P. Berg: Deoxyribonucleic acid-directed synthesis of ribonucleic acid by an enzyme from E. coli. Proc. Natl. Acad. Sci., U.S. 48: 81 94, 1962

6) Moses, R. E. \& C. C. Richardson: Replication and repair of DNA in cells of Escherichia coli treated with toluene. Proc. Natl. Acad. Sci., U.S. 67: 674 681, 1970

7) Moses, R. E.: Replicative DNA synthesis in a system diffusible for macromolecules. J. Biol. Chem. 247: $6031 \sim 6038,1972$

8) Dubnoff, J. S. \& U. Maitra: Isolation and properties of protein factors involved in polypeptide chain initiation in Escherichia coli. Methods Enzymol. 20: 248 277, 1971

9) Caskey, C. T.; E. Scolnick, R. Tomkins, G. Milman \& J. Goldstein: Release factors: In vitro assay and purification. Methods Enzymol. 20: 367 375, 1971

10) Jones, O. W. \& P. Berg: Studies on the binding of RNA polymerase to polynucleotides. J. Mol. Biol. 22: $199 \sim 209,1966$

11) Staudenbauer, W. L.: Novobiocin-a specific inhibitor of semiconservative DNA replication in permeabilized Escherichia coli cells. J. Mol. Biol. 96: $201 \sim 205,1975$

12) Reusser, F.: Ficellomycin and feldamycin; inhibitors of bacterial semiconservative DNA replication. Biochemistry 16: 3406 3412, 1977

13) Rinehart, Jr., K. L.; F. J. Antosz, K. Sasaki, P. K. Martin, M. L. Maheshwari, F. Reusser, L. H. Li, D. Moran \& P. F. WILEY: Relative biological activities of individual streptovaricins and streptovaricin acetates. Biochemistry 13: 861 867, 1974

14) Liao, L. L.; S. B. Horwitz \& A. P. Grollman: Gallin, a new inhibitor of Escherichia coli ribonucleic acid polymerase. Biochemistry 13: 1331 1337, 1974

15) Reusser, F.: Tirandamycin, an inhibitor of bacterial ribonucleic acid polymerase. Antimicr. Agents \& Chemoth. 10: 618 622, 1976

16) Hoeksema, H.; C. Chidester, S. A. Mizsak \& L. Baczynski: The chemistry of the rubradirins. The structures of rubransarols A and B. J. Antibiotics 31: 1067 1069, 1978 